\title{
LUIS BELTRÁN ALMERÍA: PALABRAS TRANSPARENTES. LA CONFIGURACIÓN DEL DISCURSO DEL PERSONAJE EN LA NOVELA MADRID: CÁTEDRA. 1992
}

Éste es el primer libro que publica el joven profesor de la Universidad de Zaragoza Luis Beltrán Almería. Se trata, como su título indica, de un estudio del discurso del personaje en la novela enfocado desde una perspectiva indudablemente novedosa, pues el objetivo final de la investigación de Beltrán es demostrar que las voces y pensamientos de los personajes se expresan por medio de palabras transparentes, siguiendo un método ya utilizado hace sesenta años por M. Bajtín y V. N. Voloshinov y que Beltrán intenta ahora actualizar, demostrando su utilidad y contribuyendo así a una valoración más justa del pensamiento de estes dos teóricos soviéticos que no siempre fue entendido cabal y completamente, quizás por su carácter excesivamente renovador y plural.

Pero como al lector no le será difícil sospechar, este libro es también una réplica a Transparent Minds ${ }^{1}$ de Dorrit Cohn, basada en el hecho de que Cohn, presa de un excesivo empirismo, centra su análisis en la expresión del pensamiento de los personajes por considerar que éste constituye el núcleo de la atención de la novela moderna. Frente a esta visión reduc-

' D. Cohn (1978): Transparent Minds. Princeton-N. Yersey: Princeton University Press. 
cionista, el libro de Beltrán pretende restaurar el equilibrio entre la representación de voz y pensamiento a partir de una concepción enunciativa del discurso y dialógica de la novela, heredera directa del pensamiento de Bajtín y Voloshinov. Esto determina un tipo de análisis que pasa por considerar el enunciado como producto de la experiencia histórica del autor, de forma que el discurso del personaje no sólo transparentará las actitudes vitales del ser de ficción sino también las de su autor.

A partir de esta consideración dialógica del discurso narrativo Beltrán deduce dos series de categorías, compositivas y arquitectónicas, que nos permiten estudiar la estructura de la novela desde la doble perspectiva de su historicidad y de su significado. Así, en la segunda parte del libro se analiza el desarrollo de estas categorías siguiendo su evolución a lo largo de la historia de la novela española, aunque con frecuencia se recurre a ejemplos de otras literaturas (francesa e hispanoamericana, sobre todo) con la pretensión de una mayor claridad, lo que dificulta en cambio la posibilidad de que el lector saque como conclusión una visión diacrónica y coherente de los cambios experimentados por el género en el ámbito de la literatura española. En todo caso, serían bien acogidos por el lector más estudios tan detallados como el que hace del origen y evolución del monólogo citado en ese contexto (vid. pp. 127-147).

Beltrán intenta evitar las interpretaciones de índole estructuralista que olvidan la dimensión histórica del discurso y que gramaticalizan en exceso el discurso narrativo como resultado de la aplicación de metodologías con una excesiva (y exclusiva) fundamentación lingüística, pero tampoco cae en la trampa de la solución escéptica tipo Danon-Boileau/Bouscaren ${ }^{2}$, que deja sin resolver muchos problemas, aunque le reconoce a estos autores (y a otros que apuestan por enfoques de este tipo) el mérito de aportar «un clima de aire fresco al enrarecido clima de la reproducción del discurso ajeno». Por el contrario, la concepción del papel del discurso ajeno en la novela que Beltrán proporie en este libro aspira a ser plenamente histórica en tanto que enunciativa, lo que implica la sustitución de las categorías gramaticales «tradicionales» por otras emanadas del propio discurso narrativo, así como la de ciertas categorías estructurales que demostraron ampliamente sus limitaciones funcionales por otras de índole enunciativa, estrechamente vinculadas a una consideración dialógica del discurso narrativo.

Consciente de la necesidad de encuadrar su propuesta dentro del marco epistemológico que la genera y precisamente para evitar que el lector la reciba como una tipología más, Beltrán dedica el capítulo I del libro a explicar su propia teoría del sujeto de la enunciación, el concepto de discurso literario (y opino que su distinción entre géneros primarios y secun-

${ }^{2}$ L. Danon-Boileau/J. Bouscaren (1984): «Pour en finir avec Procuste». Langages 73. 
darios, de inspiración bajtiniana, se beneficiaría mucho de las aportaciones de Walter Mignolo ${ }^{3}$ ), su dimensión narrativa $y$, como resultado de esta dimensión, la disociación del sujeto en un sujeto enunciativo y otro cognitivo, con la que pretende resolver los problemas suscitados por la voz dual, es decir, por la evidencia de que toda frase narrativa nos enfrenta con el doble problema de dilucidar ¿quién habla? y ¿quién ve?. Al mismo tiempo, Beltrán hace también una breve revisión crítica de las tipologías propuestas por Tamir y Benveniste, y alude de forma más superficial a las de Genette, Banfield y otros.

En el capítulo II se aborda ya la descripción de las leyes de la enunciación enunciada que determinan la configuración del discurso ajeno en la narrativa, basándose en la distinción bajtiniana entre categorías arquitectónicas, de índole formal o propiamente estética, y categorías compositivas o propias del material verbal que constituye los géneros del discurso. Las formas compositivas serían aquellas que nos permiten describir las distintas posibilidades enunciativas que para la materialización del discurso referido podemos registrar en la novela. Pero la principal novedad del estudio de Beltrán reside en la atendión que le presta a las categorías arquitectónicas, hasta ahora ignoradas sistemáticamente en los estudios del discurso ajeno (excepto en Voloshinov). La importancia que se le concede a estas vendría dada por el hecho de que expresan los diferentes tipos de comprensión activa del discurso personal y su evolución a lo largo de la historia. Estos tipos dependen de la posición ideológica que el artista adopta ante el mundo y que define, entre otros aspectos del discurso literario, los modos de reproducción del discurso ajeno. Así, después de analizar la propuesta de clasificación de las tendencias de percepción del discurso ajeno en la narración realizada por Voloshinov en $1929^{4}$ y de rechazarla por no distinguir entre elementos compositivos y arquitectónicos, Beltrán aborda la labor de establecer su propia tipología pero interrelacionándola con la de las categorias compositivas que ya formulara previamente.

Para evitar el riesgo de quedar atrapados en el dominio de lo puramente mecánico como consecuencia de limitarnos a una simple tipologización de las categorías compositivas (riesgo este que, en mi opinión, amenazaría también en caso de limitación a las arquitectónicas), Beltrán introduce la noción de tendencia perceptiva que nos permitirá apreciar la multitud de concepciones artísticas que se expresan en la novela, siempre desde una interpretación social y no individual de la relación dialógica entre el YO y el OTRO. En consecuencia, clasifica en seis las fases perceptivas del discurso ajeno: objeto-analítica, verbal-analítica, particularizadora o mixta (estas tres ya habían sido señaladas por Voloshinov), objeto-sintética, verbal-

${ }^{3}$ W. Mignolo (1978): Elementos para una teoria del texto literario. Barcelona: Crítica.

${ }^{4}$ Vid. V. N. Voloshinov (1929): Marksizm i filosofija jazyka: Osnovnye problemy sociologicheskogo metoda v nauke o jazyke. Leningrado: Priboj. 
sintética y consonante. La adjudicación a una u otra categoría se hará en función de cuál sea el objetivo central de atención (temático, lingüístico...) y de la actitud que el sujeto cognitivo del autor adopte ante el discurso de los personajes. El capítulo II y la primera parte del libro se cierran con un interesante y desafortunadamente breve párrafo en el que se intenta esbozar una correspondencia entre las antedichas fases perceptivas y las tendencias ideológicas dominantes en cada época. Hay que lamentar su brevedad y superficialidad, pues en el conjunto del libro se nota la falta de más intentos de este tipo, sobre todo después de las expectativas generadas por el autor en el lector al plantear este tipo de conclusiones como uno de los principales objetivos de su investigación.

En la segunda parte, Beltrán aborda ya el análisis concreto de las diversas técnicas utilizadas por la novela española para reproducir el discurso ajeno, partiendo de la doble distinción entre narrativa impersonal (en $3 .^{\mathrm{a}}$ persona) y narrativa personal (en $1 .^{\mathrm{a}}$ persona) y entre $v o z$ y pensamiento. Del estudio de las técnicas llama la atención la importancia que Beltrán le concede al diálogo como categoría compositiva escasamente estudiada, comparando sus conclusiones con las de Cohn. Esta autora se convertirá en inexcusable punto de referencia, bien para utilizar sus análisis como punto de partida (vid., por exemplo, el epígrafe «Narrativa personal y género narrativo" y, por supuesto, el análisis de las categorías de la psiconarración, monólogo citado y monólogo narrado), bien para discrepar de ellos abiertamente como, por ejemplo, en lo que respecta a su distribución bipolar de los monólogos (vid., p. 176) o a la definición del monólogo citado que Cohn realiza a partir de su lectura del psicólogo ruso L. S. Vygotski.

En general, Beltrán aprovecha sus discrepancias con Cohn para distanciarse de un tipo de análisis (representado por su obra) excesivamente casuístico y empírico, desentendido de la observación atenta del entramado categorial enunciativo. Curiosamente, a pesar de ser consciente de que el estudio del narrador testigo es una de las lagunas de la tipología de Cohn, Beltrán le dedica escasamente una página y justifica tan limitada atención con el argumento de que se trata de una categoría que no plantea grandes problemas enunciativos. Frente al breve espacio que se le concede al tratamiento de esta cuestión, sorprende el prolijo resumen crítico del trabajo del M. Lips ${ }^{5}$ sobre la evolución histórica del discurso indirecto libre, claramente descompensado por su extensión respecto al resto del libro. Por otra parte, ante la insistencia de Cohn en que el tratamiento del tiempo es el criterio más apropiado para definir el monólogo-memoria frente al monólogo autobiográfico, Beltrán defiende criterios genéticos y constituyentes; en mi opinión, quizá sería más coherente establecer esta distinción en función de la actitud discursiva del enunciador, lo que implicaría una mayor presencia del criterio enunciativo $y$, por lo tanto, una mayor coherencia con

${ }^{5}$ M. Lips (1926): Le style indirecte libre. Paris: Payot. 
los objetivos generales del libro (vid., p. 190), pues ese lugar secundario, al que a veces se relega la consideración enunciativa del discurso narrativo, es una de las grandes contradicciones que afectan a la valoración de conjunto de este trabajo.

En definitiva, el análisis de Beltrán pretende mantenerse fiel al modelo bajtiniano y superar el rígido esquematismo que hace de las formas discursivas fórmulas gramaticales para comenzar a valorarlas como «unidades vivas del entramado textual», intentando encuadrar el estudio de la enunciación ajena en el marco de la Historia. Así, con la distinción entre formas arquitectónicas y compositivas Beltrán pretende evitar el riego de caer en el mecanicismo formalista. El objetivo final de su trabajo será conseguir una caracterización de los diferentes tipos de enunciación relatada que se definirán en función de las distintas tendencias perceptivas a las que nos referimos con anterioridad. Pero la articulación de las categorías arquitectónicas y compositivas no está lo suficientemente lograda, si tenemos en cuenta que la pretensión última de este estudio es detectar la dimensión histórica del género narrativo a partir de las formas arquitectónicas, sensibles a los más mínimos cambios históricos, y utilizarlas como base para entender la evolución de las formas compositivas. La profunda y demorada caracterización de las segundas hace que con frecuencia se pierda la perspectiva de la tendencia perceptiva que las determina. Por otra parte, no se llega a conseguir una visión diacrónica de la evolución del género (se nota la falta, por ejemplo, de la documentación sistemática del momento en que aparecen las distintas formas), pues las referencias históricas resultan excesivamente puntuales y parecen hechas por compromiso, aunque posiblemente estos defectos sean consecuencia del procedimiento de presentación del material. Quizá es el afán de lograr una argumentación ordenada y sistemática lo que, en última instancia, le impide a Beltrán conseguir plenamente uno de sus principales y para el lector más atractivos objetivos: el de demostrar la viabilidad de un método que nos permita «sentir el latido de la Historia en los textos literarios».

DOLORES VILAVEDRA (Universidad de Santiago) 